\title{
USING THE SKILLS OF ACADEMIC ELDERS
}

J G Hall, Professor Emeritas of Pediatrics and Medical Genetics, University of British Columbia; and Children's and Women's Health Centre of British Columbia, Department of Medical Genetics, British Columbia's Children's Hospital, Vancouver, Canada jhall@cw.bc.ca

The academic life can be very rewarding. It has many stages, and over the years, experience and wisdom are gained. Because of increasing life expectancy, new opportunities present themselves to senior academicians, therefore giving thought and preparation to becoming an academic elder is needed. There can be life after retirement!

Prof. Peter Beighton and I are of the same generation - the 'Traditional Generation' (not Boomers, or Generation X, Y or Z). ${ }^{[1,2]}$ We shared an office during our Fellowship in the mid-1960s at Johns Hopkins Hospital, Baltimore, USA, with Victor McKusick. Consequently, I am delighted to contribute to Peter's festschrift and to reflect back over some of the things we might have learned in the last 50 years. So much has changed!

It may be hard for young people to believe that we could not direct-dial on the rotary phones of the day. To call internationally, we had to go through several operators. We did not have answering machines or a message answering service. The fax was invented long after our Fellowship and email is a real newcomer. The internet has opened up a world of information, social networking and video conferencing, and raises a whole series of new issues about security and ethics.

Perhaps the most striking development since our Fellowship at Johns Hopkins has been the increase in life expectancy. When I was born in 1939, the life expectancy of a woman was 59 years. Now because I live on the west coast of Canada, my life expentancy is almost 89 years. An extra 30 years! This means, for many of us who have chosen to have an academic career, that there is an extra 30 years that previous scholars did not have. We are talking about the average, of course. So for academicians, like Peter and myself, what are the unique things that we can contribute during that extra 30 years?

Most aboriginal peoples and cultures respected their elders. Elders were very useful in primitive tribes and have been shown to be important to the surviving hunter-gatherer population. ${ }^{[3]}$ The elders' wisdom was sought because of their past experiences. They knew where game and other resources could be found. They knew what to do when disease and disaster struck. They knew how to survive famine, drought, earthquakes and typhoons.

Traditionally, women and shamans knew treatments for illnesses, as well as how to deal with psychological stresses and bizarre behaviour. Recently, it has been shown among hunter-gatherers that if grandma is alive, there is a marked increase in infant survival. ${ }^{[4]}$ This seems to be because grandma can look after the infants and free the mother to gather food and fuel. ${ }^{[3]}$ Additionally, women have passed along social and cultural traditions in most cultures. Two other large mammals in addition to humans - whales and elephants - have menopause. Both of these social mammals are matriarchal. Perhaps this reflects an important role that has evolved for elders, particularly female elders, among large mammals. ${ }^{[3]}$

As human societies have become more complex, specialised roles have developed along with a rapid progression of technologies, ${ }^{[4,5]}$ and he roles of elders have become less clear, particularly in academic settings (which have, for a long time, been extremely traditional). Each generation is moulded by the societal events and conflicts of their time. ${ }^{[2]}$ Individuals are moulded by their childhood and family experiences, work and educational characteristics, and the availabilities of ever-increasing numbers of technologies. Each individual develops different priorities, different values, and different kinds of things that give them a sense of meaning and happiness. Thus, it is useful to stop and reflect at regular intervals during a lifetime, particularly within the academic/professional life, to appreciate the importance of different stages, the evolving of work patterns, and the trajectory of one's career. ${ }^{[6]}$

The typical academic career works through various stages (trainee, instructor, assistant, associate, and full professor) and receives recognition and promotion as a reward for teaching and other academic contributions such as research, publications, and administrative and professional engagement. Academic freedom is balanced against innovations and their justification. Many academicians (in the Traditional Generation) took sabbaticals every 7 years to reflect on ways to be innovative, to learn new techniques, or to complete projects.

Traditionally, in the academic setting there has been mandatory retirement at $65-68$ years of age. In the past, most academicians retired in a way that meant they had leisure time that they had never had before - perhaps to travel, perhaps to be creative. The point at which one would retire was well known in advance so that appropriate planning was possible. Mandatory retirement has disappeared in North America. Although it still exists to some extent in Europe, there is pressure for older academicians to give up resources and tenure positions so that the younger generation can find academic jobs and start on their academic careers. 
Several years ago, I did a study of the members of the American Pediatric Society, who by nature of their membership were exceptional, productive, had positions of leadership, and had made significant contributions. ${ }^{[7]}$ In that survey, we asked what academic paediatricians over the age of 65 were doing. Approximately onethird had retired and were engaging with their community and family. Approximately one-third had continued to pursue the parts of an academic career that they really enjoyed: their research, teaching and, occasionally, administration. The last third had taken the skills that they had acquired during their careers and used them in other ways: teaching in a developing country, becoming a consultant, being the executive officer of their professional group, serving on various boards, writing, etc. (Table 1).

Each individual will take a different path; however, thinking ahead and planning for that path is very useful to the academician. This should probably begin at between 50 and 55 years of age. ${ }^{[6]} \mathrm{A}$ problem is that there have not been many models, much instruction, or a great many resources available (particularly in university human resources departments) to help academicians who are thinking about what to do in their third third. I say third third because as people are living to almost 90, a third of their life would appear to be engaged in education, preparation and planning for their career; the second third of their life is pretty much taken up with their career - their unique work path, whether they are a man or a woman; while the third part of their life span is what now becomes available to use in new and creative ways, in particular by senior academicians.

Most people plan very carefully for their education. Most people, during their career, think about their advancement and about what kinds of contributions they can make. However, many people do not give a lot of thought to retirement (except for financial planning) or about what they will be doing in retirement until almost the day of retirement. With the abolition of mandatory retirement, it has become even harder to plan because it is sort of like a weakness to retire - becoming enfeebled or 'losing face'.

Most of the research on elders (seniors/older people) has been aimed at health issues, economic issues, and how many resources are being used by them (appropriately and inappropriately). Very little research has been done to look at the unique skills and contributions that elders have and can make. Aside from the recognition that we are living longer and are healthier and happier than previous generations, it is important for individuals to feel valued and as if they are making a contribution. It has been noted that in some countries and societies where people have long life expectancies, elders have specific roles and feel valued ${ }^{[5]}$ Little attention has been given in Western modern society, or in our universities, to finding ways to use the wisdom or special talents of elders. For the academician, we need to begin to ask, 'What are the unique contributions that elders can make?' and 'How can society and universities plan to use them?'

In his 2002 book Aging Well, Vaillant ${ }^{[8]}$ characterises adult development to include achieving: (i) identity, i.e. coming to an understanding of who one really is, a sense of one's values, passions, and tasks; (ii) intimacy, which is usually reflected by having spent at least 10 years as an adult living with someone, in a relationship; (iii) career consolidation, which includes mastering the tasks involved within the world of work; (iv) generativity, which involves community building by serving as a consultant, guide, mentor or coach to young adults and others in the larger society; (iv) keeper of meaning, which is sharing a sense of history, of why things happen as they did at the time they did; and finally ( $v i)$ integrity, which is the experience of having a sense of world order, and a relationship to a larger concept. These characteristics of an elder suggest that mentoring, providing historical perspective and a broad view are useful contributions to be made by academic elders.
Table 1. Using the skills developed while on faculty or staff in new or different ways after retirement

Professional organisation/society: officer, advisor, CEO, etc.

Historian: advice, writing, recording your field

Continuing research

Space for research usually comes with grants, otherwise you may have to work out of your home

If you want grad students to help, you need to get approval from your university

Research networks/collaboration

Reviewing grants for research agencies

Long-term follow-up of previous projects/research

Ethical issues or panels related to your field

Fundraising and other development activities

'Fill-in' teaching, sessional teaching, clinical teaching and locums/ coverage for others who are sick, on sabbatical, etc.

Mentoring (both young and 'older' colleagues)

Editing and/or reviewing manuscripts

Lecturing on cruises and other travel ventures

International health or education work

Federal projects

Disease-related projects

Parent support group projects

Consultant to business or governmental agencies

Medical cases

Legal cases

Knowledge transfer and translation

Reflective, analytical and policy writing for professional groups, institutions, governments

Foundation work for hospitals and organisations

Lay groups: support, advice, boards, membership, disorder specific Inner city: working with the poor and disenfranchised

Helping to orient immigrants in your area of expertise, to language and local requirements

Mediation and counselling in official capacity

Volunteering

Holding premature babies in hospital

Docent in museums

Local senior centre

Church, mosque or synagogue, etc.

Travelling to help

Missionary work

Building houses

Educational institutions

Speaking: toastmaster, emeriti college, alumni travel and continuing education

Side considerations

Decide whether you want/need to be paid

Identify 'going' rates and model contracts

Expect to be indemnified, so you are not liable to a suit

Expenses should be reimbursed

Of course, one works on these 'ageing well' characteristics throughout life, but it can be anticipated that by the time of retirement, some progress has been made in each of these tasks. The flexibility that was 
necessary during the first two-thirds of life is equally required in the third. State of health, monetary issues and relationship stresses often surface as life moves along. Men and women are, of course, different in their approach and every individual is unique. Traditionally, the male and female roles in a society may provide different senses of accomplishment and wellbeing.

When one is beginning to think about the third third (what has been traditionally called retirement), it is often useful to take a sabbatical or a period of at least a month to reflect on 'from whence one comes and whither one will go'. It certainly is worth talking to people who have retired to find out how it has worked for them. There are many considerations: money, health maintenance and technology, for which one can plan ahead. One should be sure to have or develop a community of friends and contacts, such as a group of university emeriti, community and neighbourhood groups, or religious organisations. This would mean that there would be other elders to share successes and failures and from whom to learn.

Several years ago at the University of British Columbia, we put together a document on preparation for retirement. ${ }^{[9]}$ In it, we listed opportunities to use the skills developed as an academician, which can be used in additional ways after retirement (Table 1). There are, as well, opportunities to continue to engage in ongoing support of one's academic institution. Some of these are listed in Table 2. Just as importantly, one has to think about which things to no longer do; Table 3 lists some of these. It is a very individual choice after retirement as to what an individual actually does.

Universities need to consider the major contributions that emeriti continue to make to the reputation of the university. Hopefully, each university will celebrate and appreciate their emeriti.

Interestingly, if they have planned appropriately for finances, emeriti seem not as interested in being paid or making money as they are to maintain connection with their peers and feel valued. ${ }^{[7]}$

There are many things known to increase one's health after the age of 65 and they include eating good food, exercising, drinking alcohol in moderation, no recreational drugs (particularly no smoking) and, finally, escaping from stress. We know it, but do we do it?

As you may know, our friend Peter has been a driven academician, amazingly productive and capable of utilising his unique skills and opportunities extremely well. He has now moved along from the role of being Chief to the role of being mentor. He is taking side directions and working on interests that have developed over time from his previous areas of his interest - perhaps the most important thing in an academic career is to be flexible and to be open to new opportunities that come along. And of course, to enjoy what you are doing, which I know Peter has and does!

So I will close with the adage that it is never too early to think about retirement. In this day and age, retirement is usually not about stopping altogether, but rather shifting emphasis.

Personally, I have been retired for 12 years and I have found it necessary this year to take a year sabbatical, to get away from all the things that I had been doing in order to reflect and really concentrate on things that 'only I can do'.

As one ages, we begin to realise that many of the jobs and activities of the past should be passed along to others so that we can use our own energy more effectively; everything from house cleaning to typing the references for a paper can be passed along to others. The real questions for each individual are: 'What are the unique things to do in your elder years?', 'What to give up (along with resentment or anger)?' and 'What are the new things to take up?' The good fortune of having these additional years carries with it a unique opportunity to spend the time in the most fulfilling way
Table 2. Opportunities to engage in the ongoing support of one's institution

Sit on various university or hospital committees (awards, planning, etc.) Mentor young and middle-age colleagues about career development Orient newcomers to institutional processes and values Provide institutional memory: e.g., orient others as to: 'How to get things done?', 'What people and organisational networks exist?', 'What information exists?, 'How to get at that information?', etc.

Compile a history of your department, or the things of which you have been a part

Institutional history

Personal history

Mentor senior colleagues about successful retirement

Help with continuing education courses

Do locum coverage for colleagues during illness, sabbaticals, etc. (probably expect to be paid)

Help arrange meetings of your department's and/or school's emeriti and elders

Attend alumni gatherings as speaker or 'welcomer'

Help to vet and adjudicate grants/publications prior to their submission

Write and edit letters for academic, national and international award competitions

Table 3. Things to consider no longer doing/or participating in

Attending administrative meetings

Taking part in doctoral defences

Reviewing grants when not interested in the topic

Reviewing papers that no longer interest you

Writing letters of recommendation (only do it for people you like - no longer for those you do not know and/or do not like)

Teaching (the topics or in a form you do not enjoy)

Research (no longer obliged)

Committee work (in general or in particular)

Side considerations

It may be wise to take on only one major 'outside' activity a day

Sleep in until you feel like getting up

Do not drive during rush hour

Do not race to deadlines

Unplug your phone at $19 \mathrm{~h} 30$

Say what you mean

Stand up for your rights

Insist you have a right to the front seats on the bus

Maintain visibility (do not become that invisible 'grey' generation)

to you personally. This requires some deep thinking and regular re-examination.

1. Spector ND, Cull W, Daniels S, et al. Gender and generational influences on the pediatric workforce and practice. Pediatrics 2014;130(6):1112-1121. DOI:10.1542/peds.2013-3016

2. Mohr NM, Moreno-Walton L, Mills AM, et al. Generational influences in academic emergency medicine

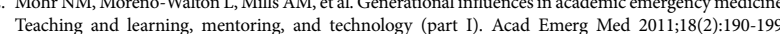
Teaching and learning, mentoring, an
DOI:10.1111/j.1553-2712.2010.00985.x

3. Bainbridge D. Marvellous middle age. New Scientist 2012;213(2855):48-51 
4. Hawkes K, O’Connell JF, Blurton Jones NG. Hadza meat sharing. Evol Hum Behav 2001:22(2):113-142. DOI:10.1016/S1090-5138(00)00066-0

5. Diamond J. The World Until Yesterday: What Can We Learn From Traditional Societies? New York Penguin Books, 2012

6. Hall JG. Trajectory of an academic career: The coming of age of academic pediatricians. JAMA Pediatr 2013:167(2):108-109. DOI:10.1001/jamapediatrics.2013.1189

. Hall JG. The challenge of developing career pathways for senior academic pediatricians. Pediatr Res

2005;57(6):914-919. DOI:10.1203/01.PDR.0000158014.46884.E5
8. Vaillant GE. Aging Well. New York: Little, Brown and Company, 2002.

9. Hall JG, Bruneau W, Chase M, et al. UBC Association of Professors Emeriti Report of Preparation for Retirement Committee. Vancouver: UBC Association of Professors Emeriti http://www.ubcemeriti. org/Preparation.html (accessed 23 October 2015).

S Afr Med J 2016;106(6 Suppl 1):S9-S12. DOI:10.7196/SAMJ.2016.v106i6.11023 